\title{
Relationships among sense of coherence, resources, and mental health in urban and rural residents in Japan
}

Yoko Sumikawa Tsuno ${ }^{1 *}$ and Yoshihiko Yamazaki ${ }^{2}$

\begin{abstract}
Background: The salutogenic model states that coping resources are defined within sociocultural and historical contexts and that various social and historical factors influence the availability of such resources. Though previous studies have suggested the need for an interregional comparison of psychological and social resources, few studies have undertaken such an investigation. The aim of this study is to investigate the associations among coping resources, sense of coherence (SOC), and health status in a comparison of urban and rural residents.

Methods: General residents (aged 30-69 years) in two areas were targeted for the current study. Through a random sampling selection, 1,000 residents from each area were picked, and an anonymous questionnaire was mailed to each resident. Ultimately, 269 and 363 valid responses from the urban and rural areas, respectively, were analyzed. SOC, both social and psychological resources, and mental health were assessed. To examine relationships between SOC and resources associated with mental health, mental health was defined as a dependent variable. Hierarchical multiple regression was conducted with variables entered from sociodemographic characteristics, social and psychological resources, and SOC.
\end{abstract}

Results: Regarding regional characteristics, social capital and participation in community activities were significantly greater in the rural area than in the urban area. Urban residents reported significantly higher self-esteem and optimism than rural residents. SOC showed the most significant association with mental health in both areas. Mental health was significantly associated with physical activity limitations and life stressors in both areas. However, the associations were weakened when social and psychological resources and SOC were added, which demonstrated their buffering effect on the negative influence of life stressors on health. When SOC was added, the association of self-esteem with mental health disappeared in both areas, but optimism in the urban area and humor in the rural area were directly and independently associated with mental health.

Conclusions: Our findings indicate that resources available to urban and rural residents are characteristic of the area where they live, and that social and psychological resources as well as SOC are associated with better mental health. Possible directions for health support strategies, reflecting regional characteristics, are suggested.

Keywords: Sense of Coherence, Salutogenic model, Regional differences, Coping resources, Mental health, Population-based study, Japan

\footnotetext{
* Correspondence: ysumikawa-tky@umin.ac.jp

${ }^{1}$ Faculty of Nursing, Toho University, Tokyo, Japan

Full list of author information is available at the end of the article
} 


\section{Background}

Traditional medicine is based on a pathogenic perspective that questions how diseases are created, and therefore, focuses on risk factors for diseases. Knowledge has been accumulated on ways to alleviate or eliminate these factors. In contrast, the salutogenic model theorized by Antonovsky looks at how health is restored, maintained, and promoted. It attempts to elucidate salutary factors, and to support and strengthen them [1]. However, it is important that pathogenic and salutogenic models develop complementarily [1]. The salutogenic model is highly valued as a basic theory for health promotion [2]. It consists of a coping ability termed "sense of coherence (SOC)" and coping resources or "generalized resistance resources," and is based on the three following assumptions. First, in the face of stressors and the resultant strain, SOC tries to cope by mobilizing generalized resistance resources. Second, the success or failure of this coping affects health, with successful coping producing positive effects on health. Third, the success or failure of coping depends on the richness of coping resources and the strength of SOC.

A person with strong SOC is better able to cope with stressors, which has a positive effect on health. Thus, SOC is also considered stress coping ability. Because SOC can strongly predict health outcomes, a number of studies have been conducted on its buffering effect on stress [3-8] and its predictive ability related to health status $[9-15]$ and well-being $[3,16]$.

In the salutogenic model, the richness of coping resources as well as the strength of SOC are considered important to the success or failure of stress coping. In general, coping resources used in the stress coping process are divided into psychological and social. Psychological resources include personality tendencies such as optimism and sense of humor as well as self-concept, which includes factors such as self-esteem and self-efficacy. Social resources include social support and social networks. A number of previous studies have examined the association of self-esteem with SOC $[11,16,17]$. This author and her colleagues found that sense of humor orientation was associated with SOC only in a rural area compared with an urban area [18]. Previous studies have reported that social support and participation in regional activities are associated with SOC $[18,19]$. However, few studies have examined the association between social capital and SOC.

A number of studies have also been conducted on the relationship of coping resources with well-being and health outcomes, indicating the importance of such resources [20]. Other studies have pointed out that a lack of coping resources can be a risk factor in the stress coping process [21]. Thus, there is a growing interest in exploring the effects of coping resources.
Previous studies have often treated SOC as one type of psychological coping resource, such as self-efficacy or self-esteem $[14,16,17]$. However, SOC in the salutogenic model is defined as the ability to mobilize coping resources in stress coping, and therefore should be distinguished from coping resources. Because SOC is the ability to mediate between coping resources and health, it is also considered a 'health promoting resource' [22] and has drawn attention from health promotion and empowerment research. Furthermore, SOC has been found relevant in resource theories [20], with regard to the ability to use coping resources as well as the usefulness of such resources.

The salutogenic model posits that coping resources are defined within sociocultural and historical contexts and that various social and historical factors influence the availability of these resources. For example, an international comparison of personality characteristics, which are considered to be psychological resources, points to the individualistic tendency of Western people and the collectivistic tendency of Japanese individuals [1]. Coping resources are different depending on the country as well as regions within the country, such as urban and rural areas. Various sociocultural differences exist in these areas, including geographical conditions and industrial structures [23].

Previous studies have suggested that an interregional comparative investigation is needed. However, few studies have actually investigated both psychological and social resources in different regions. A study by this author and her colleagues demonstrated that SOC-related factors were different between urban and rural areas. For example, economic status was correlated with SOC in urban but not rural residents, and ties with relatives and humor were correlated with SOC only in rural residents [18]. Therefore, for the purpose of providing support for residents' health, it is important to compare regions with different sociocultural backgrounds. However, it is not only important to make such a comparison, but also to identify the meaning for the generation of SOC.

The purposes of this study are to 1) distinguish social and psychological coping resources, 2) examine the availability of both types of resources, and 3) examine associations among these coping resources, SOC, and health status. By comparing urban and rural residents, the current research also attempts to examine whether regional differences influence social and psychological resources associated with health, and their relationships with SOC.

\section{Methods}

\section{Research respondents and survey method}

The general residents of 'A ward' (urban A) of Tokyo and general residents of 'B city' (rural B) of Akita prefecture were chosen for the urban respondents and rural 
respondents, respectively. Urban A was a metropolitan area with a population of 297,989 and 170,714 households with an average of 1.75 persons per household in 2006. Rural B was a rural, mountain village area with a population of 40,382 and 14,815 households, with an average of 2.73 persons per household in 2006.

Men and women aged from 30 to 69 were targeted for the current study. Through a two-step random sampling selection, 1,000 residents from each area (totaling 2,000) were picked, and an anonymous questionnaire was mailed to each resident. The survey was administered in September 2006. As a result, 269 valid responses from urban A (valid response rate: 26.9\%) and 363 valid responses from rural B (valid response rate: $36.3 \%$ ) were used for the final analysis.

This study was approved by the Graduate School of Medicine of the University of Tokyo Research Ethics Committee.

\section{Variables and measures}

The Japanese version of Antonovsky's SOC scale [2], which has 13 questions scored on a 5-point Likert scale, was used (Cronbach's $\alpha=0.85$ ) [24]. The SOC scale has been translated into almost 40 languages, and 1,300 research papers using the scale have been published. Its reliability and validity have been examined and verified $[10,25,26]$.

Data on sociodemographic characteristics were collected, including age, gender, physical activity limitations, education, economic status, marital status, and employment status.

Three social resource variables were incorporated: social capital, social support, and participation in community activities. The current study considered social capital to be an important resource that reflects regional characteristics. Therefore, it was included as one of the items to be surveyed. Social capital is the degree of connectedness and social relations in a residential area. The concept of social capital is composed of networks, trust, and norms. To measure the individual level of social capital, which is a subjective view of one's environment, a 6-item scale was used scored on a 5-point Likert scale (Cronbach's $\alpha=0.76$ ) [27]. The social support scale comprised 6 items. Five items were created based on Noguchi's [28] scale of emotional and instrumental support, and another item regarding the existence of someone in whom one has confidence was added (Cronbach's $\alpha=0.79$ ). Questions on participation in community activities included participation in "local organizations," "club activities," "helping others with celebrations or funerals," "volunteer activities," and "political activities." Answering yes to any of these items was defined as participation in regional activities, and participating in none of these items was defined as no participation in community activities.
Three psychological resource variables were incorporated: self-esteem, humor, and optimism. The Japanese version of Rosenberg's (1965) Self-Esteem Scale [29], which has 10 questions scored on a 5-point Likert scale, was used (Cronbach's $\alpha=0.85$ ). Because there are considerable cultural differences in sense of humor and its usage, humor was measured by a sense of humor scale developed in Japan [30] that questions views and attitudes toward humorous matters. It consists of three factors: "supportive humor," "playful humor," and "aggressive humor." The current study adopted the 8 items scored on a 5-point Likert scale of "supportive humor" (Cronbach's $\alpha=0.89$ ). Supportive humor represents the intention to encourage and support oneself and others, and has been found to be associated with mental health. The Life Orientation Test by Scheier et al. [31] is a representative scale that measures optimism. The Japanese revised version [32] was used, which comprises 6 items scored on a 5-point Likert scale (Cronbach's $\alpha=0.62$ ).

Life stressors were assessed by 7 items on "work," "income and family budget," "housing," "family," "reasons for living and future hope," "physical strength and health," and "life in old age." Questions were asked regarding the degree to which respondents felt worried or anxious about these items.

Mental health was measured by Goldberg's 12-item General Health Questionnaire (GHQ) [33]. The GHQ is a measure of current mental health. It has been widely applied to the general population as a scale for measuring mental health [34], although it is a screening test for psychiatric symptoms. The total score for the 12 items, rated on a 4-point Likert scale (0-3) was calculated (Cronbach's $\alpha=0.88$ ).

\section{Statistical analysis}

Urban A and rural B were separately analyzed for the regional comparison. All scores were added up, and regional differences were determined. The chi-square test was used for cross tabulation, with t-tests and the Mann-Whitney U-test used to examine differences between two groups of continuous data ( 0.05 level of statistical significance).

To examine associations between SOC and different categories of resources, multiple regression analysis was conducted with SOC as a dependent variable and variables entered from each category of demographic characteristics, social resources, and psychological resources as independent variables. Variables significantly associated with SOC and the explanatory strength of demographic characteristics, social resources, and psychological resources were examined.

To examine associations between SOC and resources related to mental health, mental health was defined 
as a dependent variable. Demographic characteristics and life stressors were defined as independent variables in Model 1. Social resources and psychological resources were added as independent variables in Model 2. Furthermore, hierarchical multiple regression was conducted with SOC as an independent variable in Model 3.

The statistical package SPSS 19.0 (IBM Japan Ltd., Tokyo, Japan) was used for data analysis.

\section{Results}

Characteristics of research respondents (Table 1)

The average age of respondents from urban A was 49.8 $(\mathrm{SD}=11.4)$ years, and that of rural $\mathrm{B}$ was $52.2(\mathrm{SD}=10.0)$ years. There was no regional difference with regard to physical activity limitations. Education and economic levels were significantly higher $(\mathrm{p}<.001)$ in urban $\mathrm{A}$. The rate of married respondents was significantly higher $(p<.001)$ in rural B (80.4\%) compared with urban A (67.9\%).

Table 1 Characteristics of research respondents

\begin{tabular}{|c|c|c|c|c|c|c|c|c|c|}
\hline \multirow[b]{3}{*}{ Age(year) } & \multicolumn{4}{|c|}{ Urban A } & \multicolumn{4}{|c|}{ Rural B } & \multirow{3}{*}{$\begin{array}{c}\begin{array}{l}\mathrm{p} \text { Value for } \\
\text { comparisor }\end{array} \\
.004\end{array}$} \\
\hline & \multirow{2}{*}{$\frac{n}{268}$} & \multicolumn{2}{|c|}{ Mean/n } & \multirow{2}{*}{$\begin{array}{l}\text { SD/\% } \\
11.4\end{array}$} & \multirow{2}{*}{$\frac{\mathbf{n}}{361}$} & \multicolumn{2}{|c|}{ Mean/n } & \multirow{2}{*}{$\begin{array}{c}\text { SD/\% } \\
10.0\end{array}$} & \\
\hline & & 49.8 & \pm & & & 52.3 & \pm & & \\
\hline Gender & 267 & & & & 361 & & & & \\
\hline Female & & 152 & & $(56.9 \%)$ & & 185 & & $(51.2 \%)$ & .158 \\
\hline Male & & 115 & & (43.1\%) & & 176 & & $(48.8 \%)$ & \\
\hline Physical activity limitations & 266 & & & & 359 & & & & \\
\hline No limitation at all & & 111 & & $(41.7 \%)$ & & 129 & & $(35.9 \%)$ & .400 \\
\hline Very little limitation & & 106 & & $(39.8 \%)$ & & 172 & & $(47.9 \%)$ & \\
\hline Some limitation & & 40 & & $(15.0 \%)$ & & 43 & & $(12.0 \%)$ & \\
\hline Severe limitation & & 9 & & $(3.4 \%)$ & & 15 & & $(4.2 \%)$ & \\
\hline Education & 260 & & & & 362 & & & & \\
\hline Junior high school & & 14 & & $(5.4 \%)$ & & 61 & & $(16.9 \%)$ & $<.001$ \\
\hline High school & & 65 & & $(25.0 \%)$ & & 196 & & $(54.1 \%)$ & \\
\hline Junior or technical college & & 73 & & $(28.1 \%)$ & & 72 & & $(19.9 \%)$ & \\
\hline Four-year university or graduate school & & 108 & & $(41.5 \%)$ & & 33 & & $(9.1 \%)$ & \\
\hline Economic status & 263 & & & & 361 & & & & \\
\hline Barely sufficient for subsistence & & 12 & & $(4.6 \%)$ & & 49 & & $(13.6 \%)$ & $<.001$ \\
\hline No difficulties with subsistence & & 59 & & $(22.4 \%)$ & & 117 & & $(32.4 \%)$ & \\
\hline Can afford some common amenities & & 141 & & $(53.6 \%)$ & & 168 & & $(46.5 \%)$ & \\
\hline Economically comfortable & & 51 & & $(19.4 \%)$ & & 27 & & $(7.5 \%)$ & \\
\hline Marital status & 262 & & & & 362 & & & & \\
\hline Married & & 178 & & $(67.9 \%$ & & 291 & & $(80.4 \%)$ & $<.001$ \\
\hline Unmarried & & 84 & & $(32.1 \%)$ & & 71 & & $(19.6 \%)$ & \\
\hline Employment status & 262 & & & & 359 & & & & \\
\hline Employed & & 240 & & $(91.6 \%)$ & & 322 & & $(89.7 \%)$ & .423 \\
\hline Unemployed & & 22 & & $(8.4 \%)$ & & 37 & & $(10.3 \%)$ & \\
\hline SOC score (range 13-65) & 269 & 42.6 & \pm & 8.1 & 363 & 41.4 & \pm & 7.8 & .058 \\
\hline Social capital (range=6-30) & 263 & 19.8 & \pm & 4.4 & 358 & 22.9 & \pm & 4.1 & $<.001$ \\
\hline Social support $($ range $=0-6)$ & 268 & 4.2 & \pm & 1.9 & 361 & 4.0 & \pm & 1.9 & .125 \\
\hline Community activities & 268 & & & & 356 & & & & \\
\hline Participation & & 107 & & (39.9\%) & & 279 & & $(78.4 \%)$ & $<.001$ \\
\hline None & & 161 & & $(60.1 \%)$ & & 77 & & $(21.6 \%)$ & \\
\hline Self-esteem (range=10-50) & 268 & 35.0 & \pm & 6.8 & 360 & 31.7 & \pm & 6.0 & $<.001$ \\
\hline Humor (range=8-40) & 269 & 26.6 & \pm & 6.1 & 360 & 26.0 & \pm & 6.6 & .255 \\
\hline Optimism (range=6-30) & 268 & 19.0 & \pm & 3.5 & 361 & 17.4 & \pm & 3.3 & $<.001$ \\
\hline Life stressors (range 0-14) & 268 & 7.5 & \pm & 3.4 & 360 & 8.3 & \pm & 3.4 & .004 \\
\hline Mental health (GHQ) (range 0-36) & 269 & 13.3 & \pm & 5.5 & 363 & 13.6 & \pm & 5.5 & .506 \\
\hline
\end{tabular}


As for social resources, there was no significant difference between the two areas with regard to social support. However, social capital and participation in community activities were significantly greater $(\mathrm{p}<.001)$ in rural $\mathrm{B}$. As for psychological resources, urban A residents reported significantly higher $(\mathrm{p}<.001)$ self-esteem and optimism than rural B residents. There was no significant difference between the two areas with regard to humor.

No significant difference was found between the two areas related to SOC and mental health.

\section{Associations of SOC and resources (Table 2)}

Age, physical activity limitations, and economic status showed significant associations with SOC in both areas. In urban $\mathrm{A}$, being married $(\beta=.12, \mathrm{p}=.027)$ was also significantly associated with SOC.

As for social resources, social capital and social support were significantly associated with SOC in both areas. Social capital was more strongly associated in rural $\mathrm{B}(\beta=.29, \mathrm{p}<.001)$ than in urban $\mathrm{A}(\beta=.14, \mathrm{p}=.019)$. Participation in community activities was significantly associated with SOC in urban A ( $\beta=.14, \mathrm{p}=.028)$, but not in rural B.
As for psychological resources, self-esteem (urban A: $\beta=.60, \mathrm{p}<.001$; rural $\mathrm{B}: \beta=.48, \mathrm{p}<.001$ ) was most significantly associated with SOC in both areas. Optimism was significantly associated with $\mathrm{SOC}$ in urban $\mathrm{A}(\beta=.13, \mathrm{p}=.018)$, but not in rural B. No significant association of humor with SOC was found in the urban or rural area.

Adjusted $R^{2}$ of sociodemographic characteristics was stronger in urban A (adjusted $\mathrm{R}^{2}=.29$ ) than in rural $\mathrm{B}$ (adjusted $R^{2}=.15$ ), but that of social resources in rural $B$ (adjusted $R^{2}=.11$ ) was stronger than in urban $A$ (adjusted $R^{2}=.06$ ). Psychological resources had the strongest explanatory power (urban A: adjusted $\mathrm{R}^{2}=.46$; rural B: adjusted $R^{2}=.29$ ) on SOC in both areas.

\section{Resources associated with mental health}

In urban A, results of hierarchical multiple regression showed that mental health was significantly associated with age, physical activity limitations, economic status, and life stressors in Model 1. With social and psychological resources added to Model 2, its significant association with economic status disappeared, but mental health was significantly associated with self-esteem and

Table 2 Associations of SOC and resources

\begin{tabular}{|c|c|c|c|c|}
\hline & \multicolumn{2}{|c|}{ Urban A ( $n=363)$} & \multicolumn{2}{|c|}{ Rural B ( $n=269)$} \\
\hline & $\beta$ & p Value & $\beta$ & p Value \\
\hline \multicolumn{5}{|l|}{ Sociodemographic characteristics } \\
\hline Gender ( $1=$ Male, $0=$ Female) & -.09 & .125 & .10 & .052 \\
\hline Age (years) & .35 & $<.001$ & .19 & $<.001$ \\
\hline Physical activity limitations (1 No limitation at all 4 Severe limitation) & -.20 & $<.001$ & -.25 & $<.001$ \\
\hline \multicolumn{5}{|l|}{ Education } \\
\hline \multicolumn{5}{|l|}{ Junior high school (ref) } \\
\hline High school & .07 & .593 & .06 & .407 \\
\hline Junior or technical college & .10 & .434 & .12 & .080 \\
\hline Four-year university or graduate school & .11 & .398 & .03 & .636 \\
\hline Economic status (1 Barely sufficient for subsistence 4 Economically comfortable) & .26 & $<.001$ & .22 & $<.001$ \\
\hline Marital status ( $1=$ Married, $0=$ Unmarried) & .12 & .027 & -.03 & .614 \\
\hline Employment status $(1=$ Employed, $0=$ Unemployed $)$ & .08 & .183 & .03 & .505 \\
\hline Adjusted $\mathrm{R}^{2}$ & .29 & & .15 & \\
\hline \multicolumn{5}{|l|}{ Social resources } \\
\hline Social capital & .14 & .019 & .29 & $<.001$ \\
\hline Social support & .15 & .012 & .12 & .025 \\
\hline Community activities ( $1=$ Participation, $0=$ None) & .14 & .028 & .03 & .546 \\
\hline Adjusted $R^{2}$ & .06 & & .11 & \\
\hline \multicolumn{5}{|l|}{ Psychological resources } \\
\hline Self-esteem & .60 & $<.001$ & .48 & $<.001$ \\
\hline Humor & .04 & .458 & .06 & .198 \\
\hline Optimism & .13 & .018 & .07 & .219 \\
\hline Adjusted $R^{2}$ & .46 & & .29 & \\
\hline
\end{tabular}

According to multiple regression analysis, SOC score as dependent variable. 
optimism. With SOC added to Model 3, the significant association of mental health with optimism was unchanged, but the significant association with self-esteem disappeared. There was a significant association between SOC and mental health.

In rural $\mathrm{B}$, mental health was found to be significantly associated with physical activity limitations and life stressors in Model 1. In Model 2, the significant associations with physical activity limitations and life stressors were unchanged, and mental health also showed significant associations with self-esteem and optimism. With SOC added to Model 3, the significant association with physical activity limitations was unchanged, but the significant association with life stressors disappeared. Mental health was significantly associated with SOC.

Model 3 (full model) revealed the strongest association between mental health and SOC in both areas (urban A: $\beta=-.30, \mathrm{p}<.001$; rural $\mathrm{B}: \beta=-.41, \mathrm{p}<.001)$.

\section{Discussion}

Regarding regional characteristics, social capital was significantly greater in rural B. According to the 2001 Cabinet Office Survey, social capital is likely to be less in big cities such as Tokyo and Osaka and higher in the countryside. The results of the current study reflect this reported trend. Participation in regional activities was significantly higher in rural B. Activities in that area typically had a close connection with the local region, such as neighborhood associations, neighborhood cleaning, and helping with ceremonial events. In urban A, activities were typically centered on individual roles and activities, such as clubs and parent-teacher associations. These findings show that social resources for rural B residents were closely dependent on the region where they lived. In contrast, urban A residents were more likely to obtain social resources more centered on individual roles and not closely related to the region. The same trends in a rural compared with an urban area have been reported by a previous study [18].

Urban A residents showed significantly higher selfesteem and optimism than rural B residents. This suggests that high self-esteem and optimism are a part of urban personality characteristics. Urban residents are likely to be more individualistic than rural residents. Rural residents tend to have more relatives in their vicinity and are likely to be more collectivistic than urban residents. Coping strategies were found to be different among urban and rural residents. Not only psychological resources, but also the structure of social resources, such as support networks and community activities, can be different as well [35]. The results of the current study reflect these reported characteristics.

As shown in Table 2, age, physical activity limitations, and economic status showed significant associations with SOC in both areas. Some studies have reported that education and SOC are directly associated $[15,36]$. However, another study indicated that higher education has an indirect effect on SOC through the occupation obtained after finishing schooling [36]. In the current study, economic status was found to be significantly associated with SOC in both areas. Although there was no direct association between education and SOC, education and economic status were associated with each other. It is reasonable to suppose that education affected economic status, and then SOC.

As for social resources, social capital and social support were significantly associated with SOC in both areas, with social capital more strongly associated in rural B than in urban A. It is probable that situation-related social capital holdings affected the degree of association with SOC. This seems to be reflected by regional characteristics of rural B. Participation in community activities was significantly associated with SOC in urban A, but not in rural B. Participation in community activities such as neighborhood associations and ceremonial events were an obligatory part of living in rural B. Almost $80 \%$ of the rural residents participated in such activities. It is possible, however, that these activities did not always have positive meaning for rural residents. In contrast, there were no community activities for urban A residents unless they were willing to participate in such activities. Therefore, participation in community activities in urban A might have had more positive meaning, and therefore was significantly associated with SOC.

As for psychological resources, self-esteem was most significantly associated with SOC in both areas. Optimism was significantly associated with $\mathrm{SOC}$ in urban A, but not in rural B. No significant association of humor was found in the urban or rural area. As for psychological resources, a previous study [16] indicated associations of SOC with optimism and sense of humor. In the current study, there was a strong association between self-esteem and SOC, and self-esteem was significantly associated with optimism and humor. When self-esteem was adjusted, there was no significant association of SOC with optimism and humor. It is probable that psychological resources had the strongest explanatory power related to SOC because self-esteem was most strongly associated. The explanatory power of demographic characteristics was stronger in urban A than in rural B, but that of social resources in rural B was stronger than in urban $\mathrm{A}$, which confirms the results of a previous study [18]. The association of SOC and resources reflected situation-related resource holdings in each area.

SOC showed the most significant association with mental health in both areas. Mental health (Table 3) showed significant associations with physical activity limitations and life stressors in both areas, but the associations were weakened when social and psychological 
Table 3 Resources associated with mental health among urban and rural respondents

\begin{tabular}{|c|c|c|c|c|c|c|c|c|c|c|c|c|}
\hline & \multicolumn{6}{|c|}{ Urban A (n=363) } & \multicolumn{6}{|c|}{ Rural B (n=269) } \\
\hline & \multicolumn{2}{|c|}{ Model 1} & \multicolumn{2}{|c|}{ Model 2} & \multicolumn{2}{|c|}{ Model 3} & \multicolumn{2}{|c|}{ Model 1} & \multicolumn{2}{|c|}{ Model 2} & \multicolumn{2}{|c|}{ Model 3} \\
\hline & $\beta$ & $p$ & $\beta$ & $\mathrm{p}$ & $\beta$ & $p$ & $\beta$ & $p$ & $\beta$ & $\mathrm{p}$ & $\beta$ & $p$ \\
\hline \multicolumn{13}{|l|}{ Sociodemographic characteristics } \\
\hline Gender ( $1=$ Male, $0=$ Female) & .06 & .350 & .07 & .240 & .03 & .536 & -.08 & .097 & -.07 & .160 & -.05 & .291 \\
\hline Age (years) & -.24 & $<.001$ & -.20 & $<.001$ & -.13 & .037 & -.04 & .461 & -.03 & .624 & .02 & .649 \\
\hline Physical activity limitations & .32 & $<.001$ & .29 & $<.001$ & .25 & $<.001$ & .33 & $<.001$ & .30 & $<.001$ & .28 & $<.001$ \\
\hline \multicolumn{13}{|l|}{ Education } \\
\hline \multicolumn{13}{|l|}{ Junior high school (ref) } \\
\hline High school & .05 & 688 & .08 & .522 & .11 & .362 & -.01 & .941 & .00 & .948 & .08 & .225 \\
\hline Junior or technical college & .00 & .989 & .08 & .526 & .11 & .376 & -.06 & .415 & -.02 & .774 & .05 & .393 \\
\hline Four-year university or graduate school & .02 & .912 & .13 & .341 & .14 & .270 & .03 & 609 & .05 & .389 & .09 & .107 \\
\hline Economic status & -.15 & .015 & -.06 & .301 & -.05 & .402 & -.06 & .250 & -.01 & .891 & -.01 & .903 \\
\hline Marital status & .03 & .573 & .09 & .095 & .09 & .094 & -.06 & .241 & -.04 & .382 & -.06 & .201 \\
\hline Employment status & -.10 & .086 & -.09 & .082 & -.08 & .133 & .00 & .959 & .01 & .890 & .02 & .613 \\
\hline Life stressors & .27 & $<.001$ & .19 & .003 & .15 & .015 & .32 & $<.001$ & .22 & $<.001$ & .09 & .085 \\
\hline \multicolumn{13}{|l|}{ Social resources } \\
\hline Social capital & & & .05 & .362 & .04 & .402 & & & -.02 & .640 & .01 & .761 \\
\hline Social support & & & .00 & .958 & .02 & .672 & & & -.07 & .184 & -.04 & .391 \\
\hline Community activities & & & -.03 & .626 & .00 & .940 & & & -.02 & .670 & -.04 & .358 \\
\hline \multicolumn{13}{|l|}{ Psychological resources } \\
\hline Self-esteem & & & -.26 & $<.001$ & -.12 & .088 & & & -.21 & $<.001$ & -.05 & .373 \\
\hline Humor & & & -.06 & .289 & -.05 & .312 & & & -.11 & .020 & -.10 & .023 \\
\hline Optimism & & & -.16 & .012 & -.13 & .029 & & & -.08 & .174 & -.07 & .163 \\
\hline SOC score & & & & & -.30 & $<.001$ & & & & & -.41 & $<.001$ \\
\hline Adjusted $\mathrm{R}^{2}$ & .36 & & .46 & & .49 & & .31 & & .40 & & .49 & \\
\hline$\Delta R^{2}$ & & & .11 & & .04 & & & & .10 & & .09 & \\
\hline
\end{tabular}

According to hierarchical multiple regression analysis, mental health (GHQ) score as dependent variable.

resources and SOC were added, which demonstrated their buffering effect on the negative influence of life stressors on health. When SOC was added, the association of self-esteem with mental health disappeared in both areas, but optimism in urban $\mathrm{A}$ and humor in rural B independently showed direct associations with mental health. SOC has been demonstrated to have a strong association with self-esteem [16,17] and is believed to be associated with mental health as an intermediary. The present results clearly show an association between better mental health and SOC. That is, the stronger SOC was, the less was the incidence of poorer mental health, consistent with findings in previous studies [11-13].

The current study shows that resources available to urban and rural residents are characteristic of the region where they live, and that social and psychological resources, as well as SOC, are associated with positive health. SOC was found to be significantly associated with social and psychological resources in both areas, playing an important function in mediating resources for better mental health. These findings confirm premises in Antonovsky's salutogenic model and represent a valuable contribution of the current research.

In this study, response rates were relatively low, and the two groups of respondents were selected from only one urban and one rural region, which may limit the generalizability of our results. Further study is necessary, involving a more comprehensive population sample, with particular attention to assessing the reproducibility or significance of our findings. The focus of the current study was regional differences. However, it is anticipated and recommended that future studies make comparisons with previous studies by incorporating gender and age differences as well $[16,19,37]$.

\section{Conclusions}

The current study confirmed that resources available to urban and rural residents are characteristic of the area where they live, and that social and psychological resources, as well as SOC, are associated with better mental health. For the practical purpose of promoting good health of 
residents in a region, it is important to strengthen social resources in that region or compensate for resources that are lacking. Participation in regional activities may have more special, positive meaning for urban residents than for rural residents. It is possible that new social resources for urban residents can be cultivated by increasing their individual involvement with the region. Possible interventions might include facilitating exchange with neighbors among urban residents. Rural residents showed greater social capital and a higher rate of participation in community activities. In addition, those who had strong attachment to or confidence in their region were likely to have high SOC and better health. It is desirable that residents maintain such ties with their region. It will be important that not only participation in regional activities, but also the qualities of the resources be examined as to whether they are in fact the resources leading to better mental health. Possible interventions might include facilitating humor among urban residents and promoting optimism among rural residents. Health strategy that takes into account also the promotion of psychological resources is expected.

This study examined associations among health resources, SOC, and mental health in two socioculturally different areas. Possible directions for health support strategies, which reflect regional characteristics, were suggested.

\section{Competing interests}

The authors declare that they have no competing interests.

\section{Authors' contributions}

Both authors contributed to the research design, interpretation of data, and drafts of the paper. YT performed the statistical analyses. All authors read and approved the final manuscript.

\section{Acknowledgements}

This work was supported by KAKENHI(A) No. 18203028. It was externally peer reviewed.

\section{Author details \\ ${ }^{1}$ Faculty of Nursing, Toho University, Tokyo, Japan. ${ }^{2}$ Faculty of Social Welfare, Nihon Fukushi University, Aichi, Japan.}

Received: 16 April 2012 Accepted: 20 December 2012

Published: 23 December 2012

\section{References}

1. Antonovsky A: Unraveling the Mystery of Health. San Francisco: Jossey-Bass; 1987.

2. Yamazaki Y: Salutogenesis as new perspectives on health and sense of coherence. Qual Nurs 1999, 5:825-832.

3. Gana K: Is sense of coherence a mediator between adversity and psychological well-being in adults? Stress Heal 2001, 17:77-83.

4. Mcsherry W, Holm J: Sense of coherence: its effects on psychological and physiological processes prior to, during, and after a stressful situation. J Clin Psychol 1994, 50:476-487.

5. Kivimaki M, Kalimo R, Toppinen S: Sense of coherence as a modifier of occupational stress exposure; stress perception, and experienced strain: a study of industrial managers. Psychol Rep 1998, 83:971-981.

6. Torsheim T, Aaroe L, Wold B: Sense of coherence and school-related stress as predictors of subjective health complaints in early adolescence: interactive, indirect or direct relationship? Soc Sci Med 2001, 53:603-614.
7. Lundberg $\mathrm{O}$ : Childhood conditions, sense of coherence, social class and adult ill health: exploring their theoretical and empirical relations. Soc Sci Med 1997, 44:821-831.

8. Wolff A, Ratner P: Stress, social support, and sense of coherence. West J Nurs Res 1999, 21:182-197.

9. Langeland E, Wahl AK, Kristoffersen K, Nortvedt MW, Hanestad BR: Sense of coherence predicts change in life satisfaction among home-living residents in the community with mental health problems: a 1-year follow-up study. Qual Life Res 2007, 16:939-946.

10. Flannery RB Jr, Perry JC, Penk WE, Flannery GJ: Validating Antonovsky's sense of coherence scale. J Clin Psychol 1994, 50:575-577.

11. Eriksson M, Lindstrom B: Antonovsky's sense of coherence scale and the relation with health: a systematic review. J Epidemiol Community Health 2006, 60:376-381.

12. Carstens J, Spangenberg J: Major depression: a breakdown in sense of coherence? Psychol Rep 1997, 80:1211-1220.

13. Ristner G, Andersson R, Johansson LM, Johansson SE, Ponzer S: Sense of coherence and lack of control in relation to outcome after orthopedic injuries. Injury 2000, 31:751-756.

14. Smith $T$, Meyers $L$ : The sense of coherence: its relationship to personality, stress, and health measures. J Soc Behav Pers 1997, 12:513-526.

15. Nilsson B, Holmgren L, Westman G: Sense of coherence in different stages of health and disease in northern Sweden gender and psychological differences. Scand J Prim Health Care 2000, 18:14-20.

16. Pallant J, Lae L: Sense of coherence, well-being and personality factors: further evaluation of the sense of coherence scale. Pers Individ Dif 2002, 33:39-48.

17. Bengtsson-Tops A: The validity of Antonovsky's sense of coherence measure in a sample of schizophrenic patients living in the community. J Adv Nurs 2001, 33:432-438.

18. Tsuno YS, Yamazaki Y: A comparative study of Sense of Coherence (SOC) and related psychosocial factors among urban versus rural residents in Japan. Pers Individ Dif 2007, 43:449-461.

19. Volanen SM, Lahelma E, Silventoinen K, Suominen S: Factors contributing to sense of coherence among men and women. Eur J Public Health 2004 14:322-330.

20. Hobfoll SE: Social and psychological resources and adaptation. Rev Gen Psychol 2002, 6:307-324.

21. Hobfoll SE: The influence of culture, community, and the nested-self in the stress process: Advancing Conservation of Resources theory. Appl Psychol 2001, 50:337-370

22. Lindstrom B, Eriksson M: Contextualizing salutogenesis and Antonovsky in public health development. Health Promot Int 2006, 21:238-244.

23. Kashima Y, Kokubo T, Kashima ES, Boxall D, Yamaguchi S, Macrae K: Culture and self: Are there within-culture differences in self between metropolitan areas and regional cities? Pers Soc Psychol Bull 2004, 30:816-823.

24. Togari T, Yoshihiko Y: Examination of the reliability and factor validity of 13-item five-point version Sense of Coherence Scale. Minzoku Eisei 2005, 71:168-182.

25. Eriksson BL, Lindstrom B: Validity of Antonovsky's sense of coherence scale: a systematic review. J Epidemiol Community Health 2005, 59:460-466.

26. Feldt $\mathrm{T}$, Lintula $\mathrm{H}$, Suominen $\mathrm{S}$, Koskenvuo $\mathrm{M}$, Vahtera J, Kivimaki M: Structural validity and temporal stability of the 13-item sense of coherence scale: prospective evidence from the population-based HeSSup study. Qual Life Res 2007, 16:483-493.

27. Fujisawa Y, Hamano T, Koyabu A: Social capital of community level on subjective health perception. Kose no Shihyo 2007, 54:18-23.

28. Noguchi Y: Social support in older people - the concept and the measurement. Soc Gerontol 1991, 34:37-48.

29. Rosenberg M: Society and the adolescent self-image. Princeton, NJ: Princeton University Press; 1965.

30. Miyato M, Ueno $\mathrm{Y}$ : An examination of support function of humor: Construction of a preference scale for supportive humor. Shinrigaku Kenkyu 1996, 67:270-277.

31. Scheier MF, Carver CS, Bridges MW: Distinguishing optimism from neuroticism (and trait anxiety, self-mastery, and self-esteem) - a reevalution of the life orientation test. J Pers Soc Psychol 1994, 67:1063-1078

32. Sakamoto S, Tanaka E: A study of Japanese version of the revised Life Orientation Test. Kenko Shinrigaku Kenkyu 2002, 15:59-63. 
33. McDowell I: Psychological well-being, the general health questionnaire 225-237. In Measuring Health. 2nd edition. Edited by McDowell I, Newell C. New York: Oxford University Press; 1996.

34. Pevalin DJ: Multiple applications of the GHQ-12 in a general population sample: an investigation of long-term retest effects. Soc Psychiatry Psychiatr Epidemio 2000, 35:508-512.

35. Roussi P, Rapti F, Kiosseoglou G: Coping and psychological sense of community: An exploratory study of urban and rural areas in Greece. Anxiety Stress Coping 2006, 19:161-173.

36. Feldt T, Kokko K, Kinnunen U, Pulkkinen L: The role of family background, school success, and career orientation in the development of sense of coherence. Eur Psychol 2005, 10:298-308.

37. Wiesmann $\mathrm{U}$, Hannich $\mathrm{HJ}$ : A salutogenic view on subjective well-being in active elderly persons. Aging Ment Health 2008, 12:56-65.

doi:10.1186/1471-2458-12-1107

Cite this article as: Tsuno and Yamazaki: Relationships among sense of coherence, resources, and mental health in urban and rural residents in Japan. BMC Public Health 2012 12:1107.

\section{Submit your next manuscript to BioMed Central and take full advantage of:}

- Convenient online submission

- Thorough peer review

- No space constraints or color figure charges

- Immediate publication on acceptance

- Inclusion in PubMed, CAS, Scopus and Google Scholar

- Research which is freely available for redistribution 